\title{
Health System Challenges in the 21st Century
}

Mohammad Hosein Kalantar Motamedi ${ }^{*}$ and Zahra Danial

Trauma Research Center, Baqiyatallah University of Medical Sciences, Tehran, Iran

*Corresponding author: Mohammad Hosein Kalantar Motamedi, Professor, Trauma Research Center, Baqiyatallah University of Medical Sciences, Tehran, Iran, Tel: +982122616946; E-mail: motamedical@yahoo.com

Received date: July 25, 2016; Accepted date: September 19, 2016; Published date: September 26, 2016

Copyright: (c) 2016 Motamedi MHK et al. This is an open-access article distributed under the terms of the Creative Commons Attribution License, which permits unrestricted use, distribution, and reproduction in any medium, provided the original author and source are credited.

Citation: Motamedi MHK, Danial Z (2016) Health System Challenges in the 21st Century. Dentistry 6: 394. doi:10.4172/2161-1122.1000394

\section{Introduction}

Health system challenges entail the growing costs of health systems around the world; it has thus become one of the main concerns of health system managers and policy makers. Continued development of new and expensive healthcare technologies, greater expectations from health systems and the development of chronic diseases and difficultto-treat illnesses are among the causes for this rapid increase in costs [1].

Oral health systems today also face skyrocketing costs. This is mainly due to the dental materials which are very expensive as well as the new devices and technical instrumentation that is marketed annually. While the overall healthcare indices in the past 20 years have raised 71 folds [2] accordingly, many problems in different parts of the health system are encountered [3]. The share of people paying health care costs is extensive [4] and equity in health care and financial equity in health costs are also lacking; [5] Insurance organizations do not utilization or protect patients against unexpected costs [6].

Pharmaceutical services have faced serious challenges $[7,8]$ as well. Like other sectors of the health care system, pharmaceuticals are influenced by economic problems. Many relate to the system structure of the health care providers, inaccurate use of financial and human resources and lack of health management policies [10]. The lack of a complete referral system and clinical guidelines of suitable coverage via insurance organizations for pharmaceuticals and treatment $[11,12]$ have increased the share of people paying health care costs and pharmaceutical costs especially by the elderly [13]. High insurance cost and lack of full coverage of the insured, also precludes patients from referring to their doctor for periodic visits and for check-ups $[7,8]$.

Insurance organizations in addition to the challenges posed by the burdens of dental and medical care, also suffer from structural problems namely those that preclude full payment of the insured thus leading to out-of-pocket spending; this is especially so in dentistry [5]. Though, there have been many attempts to solve these problems in the areas of oral health care, and pharmaceuticals, significant expansion in insurance coverage has occurred [11]; however, without sufficient attention to the cause of problems, efforts to overcome them are prone to fail.

\section{References}

1. Frederix GW, Afzali HH, Dasbach EJ, Ward RL (2015) Development and Use of Disease-Specific (Reference) Models for Economic Evaluations of Health Technologies: An Overview of Key Issues and Potential Solutions. PharmacoEconomics 1: 778-781.

2. Central Bank of Islamic Republic of Iran (2012) The main economic indicators.

3. Dastjerdi MV (2011) Family physician.

4. Mohseni A (2011) 5 percent of Iranian population go under poverty line each year because of health expenditures.

5. Fatemi A, Khodayari L, Stewart A (2015) Counseling in Iran: History Current Status, and Future Trends. J Couns Dev 93: 105-113.

6. Folland S, Goodman AC, Stano M (2007) The economics of health and health care. New York: Pearson Prentice Hall pp: 215-240.

7. Davari M, Maraci MR, Amini MS, Aslani A (2011) Evaluation of equity in pharmaceutical services in selected cities of Kurdistan (Iran) province [Doctoral Thesis]. Isfahan: School of Pharmacy and Pharmaceutical Sciences, Isfahan University of Medical Sciences.

8. Tofighi S, Zaboli R, Mahdavi MR, Moradi M, Rezapoor A, et al. (2015) The Healthcare Costs in the Aging Based on Data from the Urban Health Equity Assessment and Response Tool Project in Tehran, Iran (UHEART-2). IJMR 8: 2.

9. Davari M, Haycox A, Walley $\mathrm{T}$ (2011) Issues related to health care delivery system in Iran; past experiences, current challenges and future strategies. Iran J Public Health 41:1-9.

10. Keshavarzian M, Mofidian S (2015) An Overview on Iran Health Care Financing System: Challenges and Solutions. JHPSH 24: 1.

11. Davari M, Walley T, Haycox A (2011) Pharmaceutical Policy and Market in Iran: past experiences and future challenges. J Pharm Health Serv Res 2: 47-52.

12. Seyedifar M, Nikfar S, Abdollahi-Asl A, Rasekh H, Ehsani A, et al. (2015) An evaluation of policies and procedures of successful pharmaceutical exporters and the comparison of Iranian counterpart policy. JPPM 1:39-44.

13. Danial Z, Motamedi MH, Mirhashemi S, Kazemi A, Mirhashemi AH (2014) Ageing in iran. Lancet 384: 1927. 